\title{
THE BERLIN CN-VAN-DE-GRAAFF INJECTOR
}

\author{
D. HILSCHER, D. RENNER and B. SPELLMEYER \\ Hahn-Meitner-Institut für Kernforschung Berlin, \\ Bereich Kern- und Strahlenphysik, \\ Germany
}

\begin{abstract}
Résumé. - L'accélérateur Van-de-Graaff du type $\mathrm{CN}$ de Berlin a été transformé en injecteur d'ions lourds. Les éléments principaux de cette transformation, le tube accélérateur à vide élevé, le système de pompage différentiel, la nouvelle géométrie du spinning et le système de contrôle par calculateur seront décrits.
\end{abstract}

\begin{abstract}
The Berlin CN-Van-de-Graaff accelerator has been converted into a heavy ion injector. Main parts of this conversion including the high vacuum tube, the differential pumping system, the new geometry of the spinning and the computer control philosophy are described.
\end{abstract}

1. Introduction. - The Berlin CN-Van-de-Graaff has been converted into an injector for a four sector split pole cyclotron. The combination of both accelerators make up the Berlin heavy ion facility VICKSI which will be able to accelerate ions with masses between $A=1-40$ at energies up to $200-300 \mathrm{MeV}$.

The design aim for the conversion of the injector has been : [1] maximum voltage of $6 \mathrm{MV}$ easily obtainable, [2] heavy ion beam currents of $10 \mathrm{p \mu A}$, [3] short access time to the heavy ion source and other equipment in the high voltage terminal, that means turn around times for the gas handling system of 2-3 h, [4] increased space within the terminal (the spinning length has been increased from $1.5 \mathrm{~m}$ to $3 \mathrm{~m}$ ), increased power $(4 \rightarrow 7 \mathrm{~kW})$ and cooling capacity and [5] complete computer control of the Van-deGraaff. All these specifications have been fulfilled, though $6 \mathrm{MV}$ seems to be somewhat marginal whereas 5.8 MV is easily obtainable. In the following a short description will be given of the accelerating tube, the differential pumping system, problems with the stability of the column, and the computer control philosophy. Several descriptions of the CN conversion program have been given in $[1,2]$ and a detailed description is forth coming.

2. High Vacuum Accelerating Tube. - The requirements [1] and [2] made it necessary to replace our old HVEC accelerating tube by an ultra high vacuum tube from NEC. For the potential distribution of this tube within the $\mathrm{CN}$ column we used during an $850 \mathrm{~h}$ testing period the standard NEC open three needle corona system. It turned out that we had to reduce the gas pressure $\left(70 \% \mathrm{~N}_{2}, 20 \% \mathrm{CO}_{2}\right.$, $10 \% \mathrm{SF}_{6}$ ) by a factor of 1.7 after $500 \mathrm{~h}$ in order to obtain the same corona current at the same voltage.
This may be due to the large amount of belt dust in the $\mathrm{CN}$ and/or to the fact that during a spark a considerable amount of current goes through the corona chain. Because of these difficulties we replaced the corona system by a resistor chain of $3 \times 200 \mathrm{M} \Omega$ Welwyn resistors per accelerating gap. Tests have shown that these MOX-resistors are most spark resistent of all resistors we tested within our geometry (see Figs. 1 and 2). Our experience with this resistor potential distribution has been very successfull.

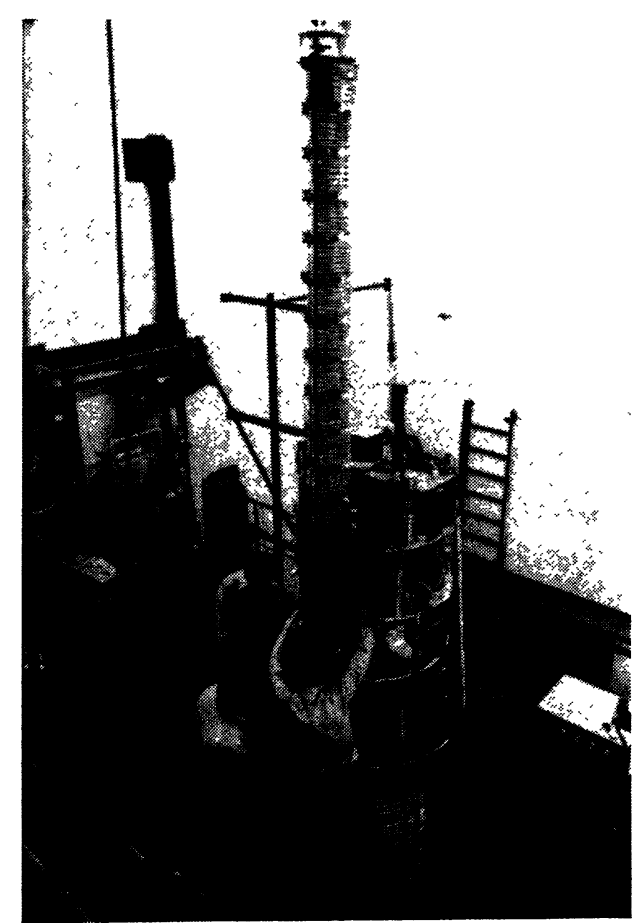

FIG. 1. - Tube being lowered into the column. 


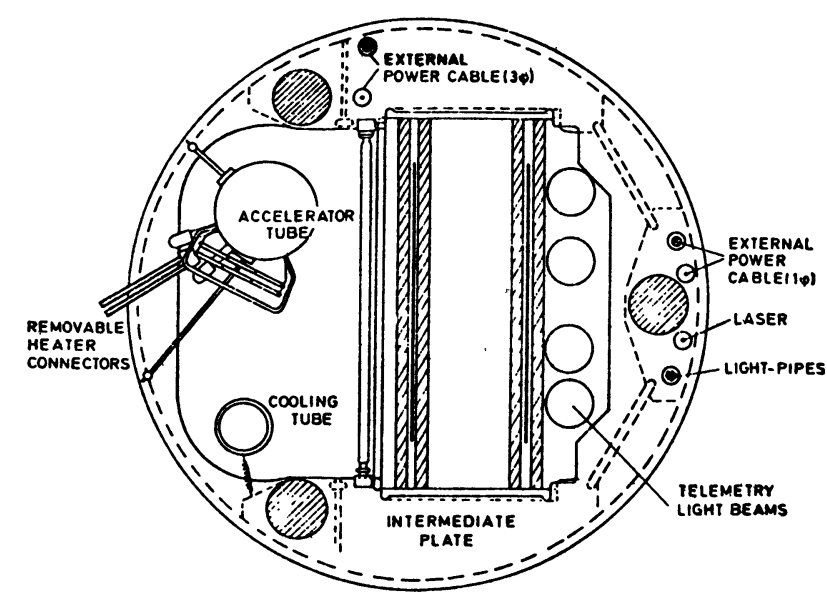

FIG. 2. - CN-column cross sections at the intermediate plate. Total diameter of the column is $1 \mathrm{~m}$.

3. Differential Pumping System. - The vacuum averaged over the total length of the accelerating tube $(4 \mathrm{~m})$ is $\sim 1 \times 10^{-8}$ torr. This required a differential pumping system between the accelerating tube and the ion source as well as the beam line system where the vacuum is $10^{-5}$ or $10^{-7}$ torr, respectively. In the terminal the differential pumping system consists of 3 ion getter pumps with pumping speeds between 90 and $180 \mathrm{l} / \mathrm{s}$ and a turbo molecular pump with $450 \mathrm{l} / \mathrm{s}$ and orifices in between with flow speeds of 0.1 to $1 \mathrm{l} / \mathrm{s}$. The essential point however was the development of a mechanical pumping system which pumps directly on the ion source where continously gas including noble gases such as $\mathrm{He}, \mathrm{Ne}$ and $\mathrm{Ar}$ of a few $\mathrm{cm}^{3}$ at NTP is let in.

A schematic diagram of the turbo molecular pumping system is shown in figure 3 . The turbo pump is a standard $450 \mathrm{l} / \mathrm{s}$ Leybold turbo molecular pump with a reinforced chamber. The fore pump is a standard Alcatel $4 \mathrm{~m}^{3} / \mathrm{h}$ pump with a special pressure chamber. A $400 \mathrm{~Hz}$ motor has been built in order to obtain $1500 \mathrm{rpm}$ for the pump. The outlet of the fore pump is stored in a pressure tight reservoir bottle $(21)$ which is also connected with the motor chamber. During a running period of about $200 \mathrm{~h}$ the pressure in this bottle increases to about $1.5 \mathrm{~atm}$. As the lifetime of the ion source is also about 150$200 \mathrm{~h}$ this is no limitation. When the turbo pump or the power in the terminal is shut off that means the drive motor is shut off a battery powered automatic valve is being closed in the beam line between the turbo and the ion getter pump vacuum region preventing backstreaming gas to the accelerating tube. However the turbo pump is not vented with $\mathrm{N}_{2}$ which endangeres backstreaming of oil vapors from the fore vacuum region of the turbo pump (the fore pump is seperated by a return valve). An analysis of the residual gas showed that the partial pressure of hydrocarbons at the turbo pump is less than $1 \%$.

A special cooling system is being used for the turbo and fore pump. At ground the isolating gas is being

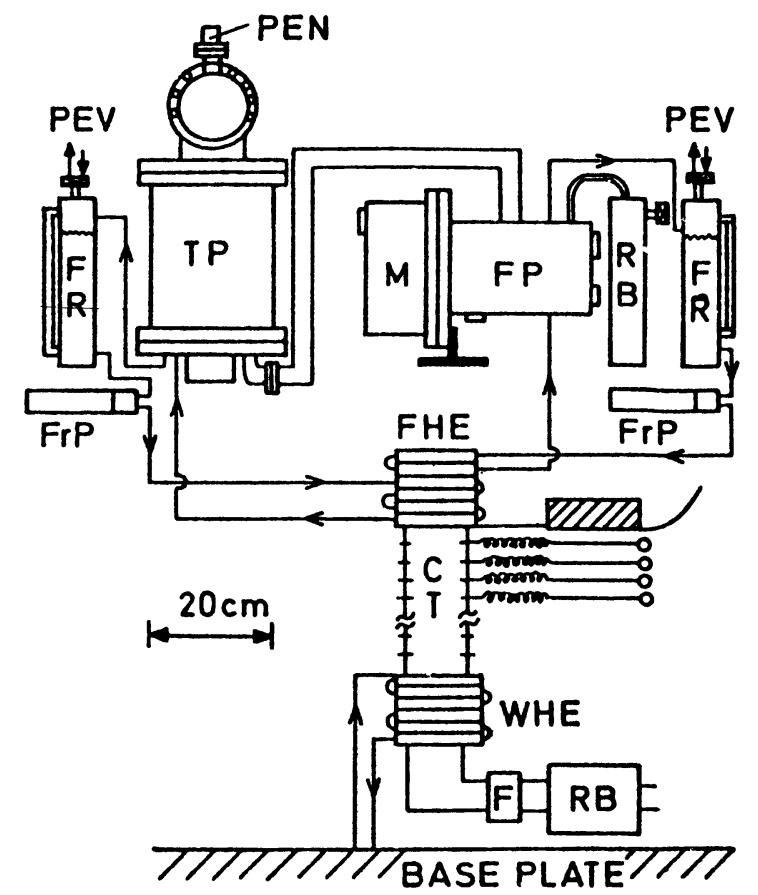

FIG. 3. - Turbo molecular pumping system in the high voltage terminal of the CN. This system is being used up to pressures of 16 atmospheres. TP : 450 l/s turbo pump (Leyboldt), $M$ and FP : $400 \mathrm{~Hz}$ motor and the $4 \mathrm{~m}^{3} / \mathrm{h}$ forepump encapsulated in pressure tight chambers, RB : reservoir bottle for the fore pump outlet, FR : freon reservoir, PEV : pressure equalizer valves which limit the pressure difference between the freon and the gas to 1.5 atmospheres, FrP : freon pump, FHE : freon-gas heat exchanger, WHE : water-gas heat exchanger, F : filter, RB : roots blower.

pumped with a blower via filters and a gas-water at $10^{\circ} \mathrm{C}$ heat exchanger through a cooling tube into the high voltage terminal where the cool gas passes through two heat exchangers between gas and freon. Two seperate freon cooling systems are used for the turbo and the fore pump. The outstreaming gas from the heat exchangers and the circulating gas from the charging belt gives enough gas circulation in the terminal so that the gas temperature at the top of the spinning is not more than $30^{\circ} \mathrm{C}$.

4. Stability of the CN Column. - A larger spinning ( $3 \mathrm{~m}$ long instead of $1.5 \mathrm{~m}$ ) has been built. The shape of this spinning was determined by the requirement to keep the maximum electrical field small. That is why we made the radius of the spinning $10 \mathrm{~cm}$ larger than the radius of the column $(R=0.5 \mathrm{~m})$. The additional space was also badly needed by the terminal equipment. The larger spinning increased however the capacitance from 90 pico-farad to 240 picofarad. This increased not only the stored energy but also the electrostatic force which acts on the terminal if the spinning is not completely concentric within the pressure tank. In our case it increased at $7 \mathrm{MV}$ from $0.4 \mathrm{~kg} / \mathrm{mm}$ excentricity for the old spinning to $1.5 \mathrm{~kg} / \mathrm{mm}$ for the new spinning. The restoring forces are given in table $I$. The coefficient $\alpha$ gives the fraction of the excentricity $x_{0}$ at zero voltage by 
TABLE I

Restoring force $K$ of the column and the coefficients $\alpha$.

$\begin{array}{rcccc}\begin{array}{c}\text { Terminal } \\ \text { load } \\ {[\mathrm{kg}]}\end{array} & \begin{array}{c}\text { K } \\ {[\mathrm{kg} / \mathrm{mm}]}\end{array} & \alpha(7 \mathrm{MV}) & \begin{array}{c}\text { Intermediate } \\ \text { plate }\end{array} & \text { Spinning } \\ - & - & - & - & - \\ 0 & 2.0 & 3.6 & \text { no } & \text { new } \\ 560 & 2.2 & 1.9 & \text { no } & \text { new } \\ 560 & 2.2 & 0.2 & \text { no } & \text { old } \\ 1200 & 3.0 & 0.9 & \text { no } & \text { new } \\ 1200 & 7.0 & 0.3 & \text { yes } & \text { new } \\ 2000 & 10.0 & 0.2 & \text { yes } & \text { new }\end{array}$

which the terminal will be elongated due to the electrostatic force at 7 MV terminal voltage : $x_{7 \mathrm{MV}}=(1+\alpha) x_{0}$. It is obvious that with the new spinning and without the intermediate plate the stability of the $\mathrm{CN}$-column is critical. The intermediate plate is a $5 \mathrm{~cm}$ thick steel plate situated in the middle of the column. The eigenfrequency of the column with the intermediate plate and a load of 2 tons, that means the final configuration is $1 \mathrm{~Hz}$. The belt revolution frequency is $1.8 \mathrm{~Hz}$. A further increase of the restoring force by inserting additional plates would let the eigen-frequency come too close to the belt revolution frequency. At about $1 \mathrm{~Hz}$ belt revolution frequency during running up the belt the terminal oscillation amplitude increases from $\pm 0.03 \mathrm{~mm}$ to $\pm 0.1 \mathrm{~mm}$ though the belt goes in a few seconds through the resonance.

During first voltage tests of the new spinning without the intermediate column plate (see fourth row of table I) the charging belt went off from the terminal and drive motor pulley displacing the terminal by $\sim 10 \mathrm{~cm}$. It could not be shown uniquely that the cause for this accident was the eccentricity of $\sim 3 \mathrm{~mm}$ of the terminal due to the electrostatic forces. Nevertheless the intermediate plate has been put back into the column and a redundant interlock system for the belt drive motor has been built which includes the belt tensions, belt positions in the terminal and at ground, and the terminal position.

5. Computer Control. - Because of complete computer control the hardware interlock system has been built in such a way that no damage to the equipment and personal can be caused by program errors and/or computer crash down. First experiences with the computer have shown it very helpful that during a computer and/or program crash down one can read the terminal voltage, the column + tube current and the tube vacuum. These parameters are displayed on small analog instruments together with 5 further parameters of the slit control system. The terminal voltage instrument has adjustable maximum and minimum switches which shut off the belt charge or give a direct interrupt to the computer to reduce the terminal voltage by a certain fraction respectively. There are also 2 emergency shut off buttons for the belt charge and the belt drive motor. Beside these computer independent analog displays all parameters can be put on a colour TV or a small TV monitor. All parameters can be set via 2 knobs which have to be hooked to the required parameter by means of a touch panel. A detailed description of the computer control system is given by Busse et al: [3].

\section{References}

[1] HilsCher D., et al., IEEE Trans. Nucl. Sci. NS 22 (1975).

[2] VICKSI-Collaboration, 1977 Particle Accelerator Conference, Chicago (1977).

[3] Busse W., et al., IEEE Trans. Nucl. Sci. NS 22 (1975). 